\title{
Increased methylation of lung cancer-associated genes in sputum DNA of former smokers with chronic mucous hypersecretion
}

\author{
Shannon Bruse ${ }^{1 \dagger}$, Hans Petersen $^{1 \dagger}$, Joel Weissfeld ${ }^{2}$, Maria Picchi ${ }^{1}$, Randall Willink ${ }^{1}$, Kieu Do ${ }^{1}$, Jill Siegfried ${ }^{2}$,
} Steven A Belinsky ${ }^{1}$ and Yohannes Tesfaigzi ${ }^{*}$

\begin{abstract}
Background: Chronic mucous hypersecretion $(\mathrm{CMH})$ contributes to COPD exacerbations and increased risk for lung cancer. Because methylation of gene promoters in sputum has been shown to be associated with lung cancer risk, we tested whether such methylation was more common in persons with $\mathrm{CMH}$.

Methods: Eleven genes commonly silenced by promoter methylation in lung cancer and associated with cancer risk were selected. Methylation specific PCR (MSP) was used to profile the sputum of 900 individuals in the Lovelace Smokers Cohort (LSC). Replication was performed in 490 individuals from the Pittsburgh Lung Screening Study (PLuSS).

Results: CMH was significantly associated with an overall increased number of methylated genes, with SULF2 methylation demonstrating the most consistent association. The association between SULF2 methylation and CMH was significantly increased in males but not in females both in the LSC and PLuSS $(\mathrm{OR}=2.72,95 \% \mathrm{Cl}=1.51-4.91$, $p=0.001$ and $\mathrm{OR}=2.97,95 \% \mathrm{Cl}=1.48-5.95, \mathrm{p}=0.002$, respectively). Further, the association between methylation and $\mathrm{CMH}$ was more pronounced among 139 male former smokers with persistent $\mathrm{CMH}$ compared to current smokers (SULF2; OR $=3.65,95 \% \mathrm{Cl}=1.59-8.37, \mathrm{p}=0.002$ ).

Conclusions: These findings demonstrate that especially male former smokers with persistent CMH have markedly increased promoter methylation of lung cancer risk genes and potentially could be at increased risk for lung cancer.
\end{abstract}

Keywords: Methylation of gene promoters, Persistent cough and phlegm, Sputum DNA, Former smoker, Lung cancer genes

\section{Background}

Chronic obstructive pulmonary disorder (COPD) is predicted to become the third leading cause of death worldwide by 2020 [1]. Prevalence is increasing both in developing and developed countries as a result of tobacco consumption [2,3], environmental exposures such as pollution and biomass fuel smoke $[4,5]$ and the growing elderly population [6]. Clinically, COPD is defined by the presence of poorly reversible airflow obstruction, although this definition simplifies the complex causes and manifestations of the disease [7]. Chronic mucous hypersecretion $(\mathrm{CMH})$,

\footnotetext{
* Correspondence: ytesfaig@|rri.org

${ }^{\dagger}$ Equal contributors

'Lovelace Respiratory Research Institute, Albuquerque, NM, Mexico

Full list of author information is available at the end of the article
}

characterized by persistent mucous cell metaplasia in the epithelial layer and submucosal glands of the respiratory tract, is a clinically important COPD phenotype [8]. CMH leads to worse respiratory symptoms, greater susceptibility to respiratory infections, more frequent COPD exacerbations, and increased risk of mortality [9-14].

Numerous publications, and two recent meta-analyses, have determined that prior $\mathrm{CMH}$ significantly increases the risk for later lung cancer $[15,16]$. While smoking clearly contributes to both diseases, analyses controlling for smoking have demonstrated that the association between lung cancer and prior $\mathrm{CMH}$ is at least partially independent of smoking $[15,16]$. It is therefore plausible that $\mathrm{CMH}$ and lung cancer have some shared molecular pathology. Previous case-control studies of incident lung 
cancer assessing the same genes as in the current study demonstrated that promoter methylation of these genes is associated with lung cancer risk $[17,18]$.

The goal of this study was to determine whether there was any association between $\mathrm{CMH}$ and prevalence of methylation of promoters in lung cancer-predictive genes in sputum DNA of smokers. Therefore, methylation specific PCR (MSP) was used to assess promoter methylation of eleven genes in sputum samples of smokers from the Lovelace Smokers Cohort (LSC). Replication was performed in smokers from the Pittsburgh Lung Screening Study (PLuSS).

\section{Methods}

\section{Study populations}

This study is approved by the Western Institutional Review Board (Olympia, WA; \#20031684) and all subjects signed informed consent for their participation. The catchment area for the LSC was the Albuquerque, NM metropolitan area, comprising a population of approximately 850,000 persons. Inclusion criteria for entry into the current study were age 40 to 75 years, current or former cigarette smoking (with a minimum of 10 pack-years) upon entry into the study, and ability to understand English. The LSC disproportionately enrolled women ever-smokers to study the susceptibility to the development of smoking-related lung diseases since women are underrepresented in most such studies in the United States. Detailed characteristics of the LSC have been described elsewhere $[19,20]$. From the LSC cohort, 311 non-Hispanic white (NHW) individuals meeting the criteria for $\mathrm{CMH}$ were included along with 589 NHW current or former smoking controls. Current and former smoking was assessed by self-report at baseline concurrent with sputum sampling. Former smokers are those who have stopped smoking for at least 2 years prior to self-report.

Study participants for the replication cohort were from the Pittsburgh Lung Screening Study (PLuSS), a volunteer cohort established to investigate lung cancer biomarkers in an at-risk population of smokers which has previously been described [21,22]. From the total cohort $(\mathrm{n}=3638), 490$ NHW individuals (183 men and 307 women) had information allowing classification with respect to chronic mucous hypersecretion and had provided sputum for DNA isolation. Spirometric testing procedures have previously been described for both the PLuSS and the LSC $[19,21]$.

Because a unifying definition for $\mathrm{CMH}$ was not available in both cohorts two criteria were used to define $\mathrm{CMH}$ : In the LSC, CMH was defined as present in participants that had self-reported cough productive of phlegm for at least 3 months per year for at least 2 consecutive years (ie. the standard definition of chronic bronchitis). In the PLuSS, $\mathrm{CMH}$ was defined as self-reported cough productive of phlegm as assessed by both a first and second questionnaire (with a median questionnaire interval of 3.5 years), and self-reported cough producing phlegm for "most days a week" or "several days a week" in the past year, as assessed by the second questionnaire.

\section{Methylation specific PCR}

Nested MSP assays were used to detect methylation of cytosines at cytosine-phosphate-guanine sites in DNA recovered from the sputum samples, as previously described $[23,24]$. We studied the promoter methylation of a panel of eleven tumor suppressor genes with previously identified roles in predicting lung cancer risk $[17,18]$. These genes included $P C D H-20$ (Protocadherin); SULF-2 (6-O-endosulfatase 2); GATA binding protein-4 and -5 transcription factors; $P A X-5 \alpha$ and $P A X-5 \beta$ (paired box protein transcription factors); $p 16 ; M G M T$ (O (6)-methylguanine-DNA methyltransferase); DAPK (Death-associated protein kinase); DAL-1 (Differentially expressed in adenocarcinoma of the lung); and $\mathrm{JPH}-3$ (Junctophilin). Methylation by this technique was scored positive or negative, as previously described [18].

\section{Statistical analysis}

Chi-square and Fisher's exact tests were used for the univariate analyses of categorical variables, while twosample t-tests and Kruskal-Wallis tests were used for continuous variables. For multivariable analyses of $\mathrm{CMH}$, logistic regression was performed. Predictors included gene specific methylation prevalence, and also total methylation (continuous variable representing the sum of genes methylated within an individual). Additional predictors included age, education (dichotomized as at least high school or less than high school education), COPD status, sex, pack-years smoking, and current smoking status. When the LSC and PLuSS were combined for analyses adjustment for cohort was included. Model fitting iterations were performed with the $R$ package glmulti using the small sample size corrected Akiake information criterion to determine best-fitting models [25]. All statistical analyses were performed in R version 2.12.0 or SAS version 9.2.

\section{Results}

\section{$\mathrm{CMH}$ is associated with higher prevalence of gene promoter methylation in smokers}

The initial study was conducted in 900 NHW current and former smokers from the LSC with available sputum methylation data. At time of sputum collection, there were 311 smokers with and 589 smokers without $\mathrm{CMH}$. In unadjusted analysis, prevalence of SULF2 methylation was significantly higher in those with $\mathrm{CMH}$ than without $\mathrm{CMH}$ (39\% and $30 \%$ respectively, $\mathrm{p}<0.01$, Table 1 ). A replication study was performed in the PLuSS, comprised of 140 smokers with and 350 smokers without $\mathrm{CMH}$, 
Table 1 Select variables by CMH status in the LSC

\begin{tabular}{|c|c|c|c|c|c|c|c|}
\hline \multirow[t]{2}{*}{ LSC } & \multicolumn{2}{|c|}{ Total } & \multicolumn{2}{|c|}{$\mathrm{CMH}$} & \multicolumn{2}{|c|}{ No CMH } & \multirow[b]{3}{*}{$p$ value } \\
\hline & $n=900$ & $(100.0)$ & $\mathrm{n}=311$ & $(100.0)$ & $n=589$ & $(100.0)$ & \\
\hline Characteristic & $\mathrm{n}$ or mean & (\%) or (SD) & $\mathrm{n}$ or mean & (\%) or (SD) & $\mathrm{n}$ or mean & (\%) or (SD) & \\
\hline Female & 673 & $(74.8)$ & 222 & $(71.3)$ & 451 & $(76.6)$ & 0.088 \\
\hline Baseline age & 55.9 & (9.6) & 55.1 & $(9.8)$ & 56.3 & (9.4) & 0.067 \\
\hline Education $>=\mathrm{HS}^{*}$ & 663 & $(73.7)$ & 207 & $(66.6)$ & 456 & $(77.4)$ & $<0.001$ \\
\hline Obese & 278 & (30.9) & 93 & $(29.9)$ & 185 & (31.4) & 0.642 \\
\hline Pack years & 41.1 & $(20.9)$ & 44.2 & $(21.8)$ & 39.5 & $(20.2)$ & 0.001 \\
\hline Baseline smoker & 494 & $(55.6)$ & 236 & $(76.4)$ & 258 & $(44.6)$ & $<.0001$ \\
\hline Baseline COPD & 281 & $(31.2)$ & 123 & (39.6) & 158 & $(26.8)$ & $<.0001$ \\
\hline Total methylation & 2.47 & $(2.12)$ & 2.66 & $(2.22)$ & 2.37 & $(2.06)$ & 0.057 \\
\hline PCDH20 & 333 & $(37.0)$ & 125 & $(40.2)$ & 208 & $(35.3)$ & 0.149 \\
\hline SULF2 & 299 & $(33.2)$ & 122 & $(39.2)$ & 177 & $(30.1)$ & 0.005 \\
\hline GATA4 & 348 & (38.7) & 125 & $(40.2)$ & 223 & (37.9) & 0.495 \\
\hline PAX5A & 138 & (15.3) & 46 & (14.8) & 92 & (15.6) & 0.743 \\
\hline p16 & 154 & (17.1) & 61 & (19.6) & 93 & (15.8) & 0.147 \\
\hline MGMT & 249 & $(27.7)$ & 87 & $(28.0)$ & 162 & $(27.5)$ & 0.881 \\
\hline DAPK & 153 & (17.0) & 54 & (17.4) & 99 & (16.8) & 0.833 \\
\hline GATA5 & 152 & (16.9) & 55 & $(17.7)$ & 97 & $(16.5)$ & 0.643 \\
\hline PAX5B & 90 & $(10.0)$ & 30 & $(9.7)$ & 60 & $(10.2)$ & 0.797 \\
\hline DAL1 & 71 & (7.9) & 27 & (8.7) & 44 & (7.4) & 0.521 \\
\hline JPH3 & 229 & $(25.4)$ & 91 & (29.3) & 138 & $(23.4)$ & 0.056 \\
\hline
\end{tabular}

*High school.

and in unadjusted analysis, prevalence of SULF2 methylation was significantly higher in those with $\mathrm{CMH}$ than those without $\mathrm{CMH}$ ( $40 \%$ and $26 \%$ respectively, $\mathrm{p}<0.01$, Table 2).

In adjusted analysis in the LSC, total methylation (defined as the cumulative prevalence of methylation for all 11 genes; see Methods) was significantly higher in smokers with $\mathrm{CMH}$, as was methylation prevalence of SULF2, JPH3, and PCDH20 ( $<<0.05$, all analyses) (Table 3 ). Similarly, adjusted analysis in the PLuSS showed that total methylation was significantly higher in those with $\mathrm{CMH}$, as was methylation prevalence of SULF2, p16, and PCDH2O ( $<<0.05$, all analyses) (Table 3 ).

Analyses combining the two cohorts were also performed. In both unadjusted (Additional file 1: Table S1) and adjusted (Table 3 ) analysis in the combined cohorts, total methylation was higher in those with $\mathrm{CMH}$ than in those with an absence of $\mathrm{CMH}$, as was methylation prevalence of SULF2, JPH3, p16 and PCDH2O ( p < 0.01, all analyses). Additional factors associated with $\mathrm{CMH}$ were younger age, less education, having COPD, greater pack years, and current smoking $(\mathrm{p}<0.01$, all analyses, Additional file 1: Table S1). Additional modeling was performed that included two-way interaction terms for baseline COPD, pack years and methylation, total or individual gene for the combined cohort of LSC and PLuSS cohorts. These interaction terms were not significant for total methylation, Sulf-2, or PCDH20, each of which showed significant association with $\mathrm{CMH}$ within the LSC, the PluSS cohort, and the combination of both cohorts. These findings suggest methylation is an independent risk for $\mathrm{CMH}$.

\section{The association between $\mathrm{CMH}$ and gene promoter methylation is stronger in males}

Univariate analysis revealed factors that were associated with higher methylation prevalence, which include male sex $(p<0.001)$ (Additional file 1: Table S2). Because of the observed sex differences in methylation prevalence, sex stratified analyses were performed in males and females. Total methylation was significantly associated with CMH in males in both the LSC and PLuSS cohorts ( $\mathrm{p}<0.01$, both analyses) and when analysis was performed for the combined cohort $(\mathrm{p}<0.001)$ (Table 4$)$. When individual genes were analyzed in males, SULF2, p16, and $J P H 3$ were significantly associated in the LSC ( $\mathrm{p}<0.05$, all analyses), while SULF2 and PCDH20 were significant in the PLuSS $(\mathrm{p}<0.05)$. In the combined cohort, the prevalence of SULF2, JPH3, PCDH2O, and p16 methylation were all significantly higher in males with 
Table 2 Select variables by CMH status in the PLuSS

\begin{tabular}{|c|c|c|c|c|c|c|c|}
\hline \multirow[t]{2}{*}{ PLuSS } & \multicolumn{2}{|c|}{ Total } & \multicolumn{2}{|c|}{$\mathrm{CMH}$} & \multicolumn{2}{|c|}{ No CMH } & \multirow[b]{3}{*}{$p$ value } \\
\hline & $n=490$ & $(100.0)$ & $n=140$ & $(100.0)$ & $\mathrm{n}=350$ & $(100.0)$ & \\
\hline Characteristic & $\overline{\mathrm{n} \text { or mean }}$ & $\overline{(\%) \text { or (SD) }}$ & $\overline{\mathrm{n} \text { or mean }}$ & $\overline{(\%) \text { or }(\mathrm{SD})}$ & $\overline{\mathrm{n} \text { or mean }}$ & $\overline{(\%) \text { or }(\mathrm{SD})}$ & \\
\hline Female & 307 & $(62.7)$ & 90 & $(64.3)$ & 217 & $(62.0)$ & 0.637 \\
\hline Baseline age & 60.3 & $(6.4)$ & 59.5 & $(6.1)$ & 60.6 & $(6.5)$ & 0.075 \\
\hline Education $>=\mathrm{HS}^{*}$ & 474 & $(96.7)$ & 134 & $(95.7)$ & 340 & $(97.1)$ & 0.422 \\
\hline Obese & 158 & $(32.2)$ & 45 & $(32.1)$ & 113 & $(32.3)$ & 0.976 \\
\hline Pack Years & 55.9 & $(20.1)$ & 59 & $(19.1)$ & 54.6 & $(20.4)$ & 0.029 \\
\hline Baseline smoker & 335 & $(68.4)$ & 113 & $(80.7)$ & 222 & $(63.4)$ & $<0.001$ \\
\hline Baseline COPD & 238 & $(48.6)$ & 81 & $(57.9)$ & 157 & $(44.9)$ & 0.009 \\
\hline Total methylation & 2 & $(1.84)$ & 2.26 & $(2.04)$ & 1.9 & $(1.75)$ & 0.052 \\
\hline PCDH2O & 135 & $(27.6)$ & 47 & (33.6) & 88 & $(25.1)$ & 0.059 \\
\hline SULF2 & 147 & $(30.0)$ & 56 & $(40.0)$ & 91 & $(26.0)$ & 0.002 \\
\hline GATA4 & 166 & (33.9) & 47 & (33.6) & 119 & $(34.0)$ & 0.928 \\
\hline PAX5A & 68 & (13.9) & 23 & $(16.4)$ & 45 & (12.9) & 0.302 \\
\hline p16 & 92 & (18.8) & 32 & (22.9) & 60 & $(17.1)$ & 0.143 \\
\hline MGMT & 123 & $(25.1)$ & 34 & $(24.3)$ & 89 & $(25.4)$ & 0.792 \\
\hline DAPK & 75 & (15.3) & 21 & (15.0) & 54 & $(15.4)$ & 0.905 \\
\hline GATA5 & 64 & $(13.1)$ & 18 & $(12.9)$ & 46 & $(13.1)$ & 0.932 \\
\hline PAX5B & 33 & $(6.7)$ & 9 & (6.4) & 24 & (6.9) & 0.864 \\
\hline DAL1 & 37 & (7.6) & 14 & $(10.0)$ & 23 & (6.6) & 0.194 \\
\hline JPH3 & 41 & (8.4) & 15 & $(10.7)$ & 26 & (7.4) & 0.235 \\
\hline
\end{tabular}

*High school.

$\mathrm{CMH}$ compared to males without $\mathrm{CMH}(\mathrm{p}<0.05$, all analyses). Although the number of female participants was higher for both cohorts, in females, no significant associations were found for the individual cohort analyses, although higher SULF2 methylation prevalence was observed in analysis of the combined cohorts $(\mathrm{p}<0.05)$.

The association between $\mathrm{CMH}$ and gene promoter methylation is stronger in former smokers

Current smoking status and pack years were controlled for in adjusted analyses (Tables 3 and 4); however, residual confounding remains a possibility, given that current smoking strongly influences CMH status (Tables 1 and 2). Therefore, stratified analyses were performed in current and former smokers. Adjusted stratified analysis revealed for both the LSC and PLuSS that total methylation was significantly higher in those with $\mathrm{CMH}$ who were former smokers ( $<<0.05$, all analyses) (Table 5). Although the number of current smokers was greater in both cohorts, in current smokers total methylation was not significantly associated with $\mathrm{CMH}$ in either cohort or the combined analysis. In general, the associations between methylation

Table 3 Odds ratios for CMH in adjusted* analyses

\begin{tabular}{|c|c|c|c|c|c|c|c|c|c|}
\hline \multirow[b]{2}{*}{ Exposure variable } & \multicolumn{3}{|c|}{ LSC $n=900$} & \multicolumn{3}{|c|}{ PLuSS $n=490$} & \multicolumn{3}{|c|}{ Combined $n=1390$} \\
\hline & OR & (95\% CL) & $p$ value & OR & (95\% CL) & $p$ value & OR & (95\% CL) & $p$ value \\
\hline Total methylation & $1.09^{* * *}$ & $(1.02,1.17)$ & 0.014 & 1.15 & $(1.03,1.29)$ & 0.014 & 1.11 & $(1.04,1.18)$ & $0.001^{* *}$ \\
\hline SULF2 & 1.68 & $(1.23,2.30)$ & $0.001^{* *}$ & 2.14 & $(1.38,3.31)$ & $0.001^{* *}$ & 1.79 & $(1.39,2.31)$ & $<.0001^{* *}$ \\
\hline p16 & 1.43 & $(0.97,2.11)$ & 0.067 & 1.69 & $(1.01,2.83)$ & 0.045 & 1.54 & $(1.14,2.10)$ & 0.006 \\
\hline JPH3 & 1.45 & $(1.04,2.03)$ & 0.031 & 1.70 & $(0.83,3.48)$ & 0.149 & 1.53 & $(1.13,2.08)$ & 0.006 \\
\hline PCDH20 & 1.40 & $(1.03,1.90)$ & 0.033 & 1.73 & $(1.10,2.73)$ & 0.018 & 1.47 & $(1.14,1.90)$ & $0.003^{* *}$ \\
\hline
\end{tabular}

Each row represents a separate adjusted model.

LSC: CMH $(n=311)$ and no CMH $(n=589)$; PLuSS CMH $(n=140)$ and no CMH $(n=350)$.

*Additional adjustors include age, sex, education, COPD, current smoking, pack years, and cohort (for combined analysis); CMH as outcome.

**Bonferroni adjusted significance threshold is $p<0.0042$.

***Represents the odds ratio increase for each additional gene methylated. 
Table 4 Odds ratios for $\mathrm{CMH}$ in sex stratified adjusted* analyses

\begin{tabular}{|c|c|c|c|c|c|c|c|c|c|}
\hline \multirow{2}{*}{$\begin{array}{c}\text { Males } \\
\text { Exposure variable }\end{array}$} & \multicolumn{3}{|c|}{ LSC $n=227$} & \multicolumn{3}{|c|}{ PLuSS $n=183$} & \multicolumn{3}{|c|}{ Combined $n=410$} \\
\hline & OR & $(95 \% \mathrm{CL})$ & $\overline{p \text { value }}$ & OR & (95\% CL) & $p$ value & OR & $(95 \% \mathrm{CL})$ & $p$ value \\
\hline Total methylation & 1.23 & $(1.07,1.41)$ & $0.004^{* *}$ & 1.28 & $(1.07,1.54)$ & 0.008 & 1.23 & $(1.11,1.37)$ & $<.0001^{* *}$ \\
\hline SULF2 & 2.72 & $(1.51,4.91)$ & $0.001^{* *}$ & 2.97 & $(1.48,5.95)$ & $0.002^{* *}$ & 2.73 & $(1.75,4.25)$ & $<.0001^{* *}$ \\
\hline p16 & 2.08 & $(1.01,4.28)$ & 0.048 & 1.66 & $(0.71,3.89)$ & 0.246 & 1.88 & $(1.09,3.23)$ & 0.023 \\
\hline JPH3 & 2.64 & $(1.43,4.87)$ & $0.002^{* *}$ & 2.70 & $(0.96,7.59)$ & 0.059 & 2.66 & $(1.58,4.48)$ & $<.0001^{* *}$ \\
\hline PCDH20 & 1.68 & $(0.94,2.98)$ & 0.079 & 2.29 & $(1.15,4.53)$ & 0.018 & 1.89 & $(1.22,2.93)$ & $0.004^{* *}$ \\
\hline Females & \multicolumn{3}{|c|}{ LSC $n=673$} & \multicolumn{3}{|c|}{ PLuSS n= 307} & \multicolumn{3}{|c|}{ Combined $n=980$} \\
\hline Exposure variable & OR & (95\% CL) & $p$ value & OR & $(95 \% \mathrm{CL})$ & $\mathrm{p}$ value & OR & $(95 \%$ CL) & $p$ value \\
\hline Total methylation & 1.04 & $(0.96,1.14)$ & 0.324 & 1.08 & $(0.93,1.25)$ & 0.322 & 1.05 & $(0.98,1.13)$ & 0.188 \\
\hline SULF2 & 1.41 & $(0.97,2.05)$ & 0.074 & 1.72 & $(0.96,3.07)$ & 0.066 & 1.47 & $(1.07,2.01)$ & 0.016 \\
\hline p16 & 1.25 & $(0.79,1.99)$ & 0.342 & 1.76 & $(0.91,3.40)$ & 0.091 & 1.41 & $(0.97,2.05)$ & 0.073 \\
\hline JPH3 & 1.07 & $(0.71,1.62)$ & 0.748 & 1.20 & $(0.42,3.39)$ & 0.736 & 1.10 & $(0.75,1.62)$ & 0.634 \\
\hline PCDH20 & 1.33 & $(0.92,1.93)$ & 0.126 & 1.35 & $(0.72,2.52)$ & 0.346 & 1.34 & $(0.97,1.83)$ & 0.073 \\
\hline
\end{tabular}

Each row represents a separate adjusted model.

*Additional adjustors include age, education, COPD, current smoking, pack years, and cohort (for combined analysis); CMH as outcome.

**Bonferroni adjusted significance threshold is $\mathrm{p}<0.0042$.

and $\mathrm{CMH}$ were less significant and demonstrated smaller effect sizes in current smokers (Table 5). Sex and smoking stratified analysis of the combined cohorts (combined to ensure adequate sample size for analysis) (Table 6) revealed that the strongest associations between methylation and $\mathrm{CMH}$ were observed in male former smokers, with odds ratios for the individual genes ranging from 2.55 to 4.34. Despite 2-3-fold greater number of female participants in the LSC and PLuSS, only SULF-2 methylation was associated with $\mathrm{CMH}$ in females from the combined cohorts.
Sputum methylation is a sensitive and specific predictor of $\mathrm{CMH}$ in male former smokers

Receiver operator characteristic (ROC) curves were generated to assess the sensitivity and specificity of logistic regression models for discriminating $\mathrm{CMH}$. Prior to generating ROC curves, modeling was performed to assess all combinations of predictors, including all 11 genes and covariates. The Akaike information content (AICc) [25] was used to select the models with an optimal trade-off between accuracy and complexity. Independently in both the LSC and the PLuSS, the best-fitting model was

Table 5 Odds ratios for $\mathrm{CMH}$ in adjusted* analyses of current and former smokers

\begin{tabular}{|c|c|c|c|c|c|c|c|c|c|}
\hline \multirow[b]{2}{*}{ Exposure variable } & \multicolumn{3}{|c|}{ LSC former smokers $n=406$} & \multicolumn{3}{|c|}{ PLuSS former smokers $n=155$} & \multicolumn{3}{|c|}{ Combined former smokers $n=561$} \\
\hline & OR & (95\% CL) & $p$ value & OR & $(95 \% \mathrm{CL})$ & $p$ value & OR & $(95 \% \mathrm{CL})$ & $p$ value \\
\hline Total methylation & 1.13 & $(1.01,1.26)$ & 0.034 & 1.36 & $(1.10,1.67)$ & $0.004^{* *}$ & 1.18 & $(1.07,1.30)$ & $0.001^{* *}$ \\
\hline SULF2 & 1.96 & $(1.17,3.29)$ & 0.011 & 3.64 & $(1.51,8.77)$ & $0.004^{* *}$ & 2.30 & $(1.47,3.59)$ & $<.0001^{* *}$ \\
\hline p16 & 2.06 & $(1.13,3.76)$ & 0.018 & 1.53 & $(0.59,3.95)$ & 0.377 & 1.92 & $(1.16,3.17)$ & 0.012 \\
\hline JPH3 & 1.79 & $(1.04,3.09)$ & 0.037 & 2.76 & $(0.99,7.71)$ & 0.053 & 2.02 & $(1.25,3.26)$ & $0.004^{* *}$ \\
\hline \multirow[t]{2}{*}{$\mathrm{PCDH} 20$} & 1.9 & $(1.13,3.18)$ & 0.015 & 1.15 & $(0.46,2.90)$ & 0.768 & 1.67 & $(1.07,2.61)$ & 0.024 \\
\hline & \multicolumn{3}{|c|}{ LSC current smokers $n=494$} & \multicolumn{3}{|c|}{ PLuSS current smokers $n=335$} & \multicolumn{3}{|c|}{ Combined current smokers $n=829$} \\
\hline Exposure variable & OR & $(95 \% \mathrm{CL})$ & $p$ value & OR & $(95 \% \mathrm{CL})$ & $p$ value & OR & $(95 \% \mathrm{CL})$ & $\mathrm{p}$ value \\
\hline Total methylation & 1.07 & $(0.97,1.17)$ & 0.18 & 1.07 & $(0.94,1.23)$ & 0.303 & 1.07 & $(0.99,1.15)$ & 0.106 \\
\hline SULF2 & 1.53 & $(1.03,2.28)$ & 0.036 & 1.82 & $(1.09,3.04)$ & 0.022 & 1.60 & $(1.17,2.19)$ & $0.003^{* *}$ \\
\hline p16 & 1.15 & $(0.70,1.89)$ & 0.578 & 1.83 & $(0.98,3.41)$ & 0.057 & 1.39 & $(0.95,2.05)$ & 0.094 \\
\hline JPH3 & 1.3 & $(0.84,1.99)$ & 0.237 & 1.16 & $(0.42,3.19)$ & 0.779 & 1.29 & $(0.87,1.91)$ & 0.200 \\
\hline PCDH20 & 1.17 & $(0.79,1.72)$ & 0.433 & 1.98 & $(1.16,3.36)$ & 0.012 & 1.39 & $(1.02,1.90)$ & 0.039 \\
\hline
\end{tabular}

Each row represents a separate adjusted model.

*Additional adjustors include age, sex, education, COPD, pack years, and cohort (for combined analysis); CMH as outcome.

**Bonferroni adjusted significance threshold is $\mathrm{p}<0.0042$. 
Table 6 Odds ratios for CMH in sex stratified adjusted* analyses of current and former smokers

\begin{tabular}{|c|c|c|c|c|c|c|}
\hline \multirow{2}{*}{$\begin{array}{l}\text { Males } \\
\text { Exposure variable }\end{array}$} & \multicolumn{3}{|c|}{ Current smokers $n=269$} & \multicolumn{3}{|c|}{ Former smokers $n=139$} \\
\hline & OR & $(95 \% \mathrm{CL})$ & $p$ value & OR & $(95 \% \mathrm{CL})$ & $p$ value \\
\hline Total methylation & 1.13 & $(0.99,1.30)$ & 0.076 & 1.39 & $(1.16,1.67)$ & $<.0001^{* *}$ \\
\hline SULF2 & 2.52 & $(1.47,4.32)$ & $0.001^{* *}$ & 3.65 & $(1.59,8.37)$ & $0.002^{* *}$ \\
\hline p16 & 1.36 & $(0.69,2.67)$ & 0.378 & 3.69 & $(1.42,9.60)$ & 0.007 \\
\hline JPH3 & 1.97 & $(1.02,3.79)$ & 0.043 & 4.34 & $(1.74,10.79)$ & $0.002^{* *}$ \\
\hline PCDH20 & 1.71 & $(1.02,2.86)$ & 0.043 & 2.55 & $(1.11,5.83)$ & 0.027 \\
\hline Females & \multicolumn{3}{|c|}{ Current smokers $n=560$} & \multicolumn{3}{|c|}{ Former smokers $n=410$} \\
\hline Exposure variable & OR & $(95 \% \mathrm{CL})$ & $p$ value & OR & (95\% CL) & $p$ value \\
\hline Total methylation & 1.02 & $(0.93,1.12)$ & 0.617 & 1.10 & $(0.97,1.24)$ & 0.142 \\
\hline SULF2 & 1.27 & $(0.86,1.88)$ & 0.221 & 1.92 & $(1.12,3.29)$ & 0.019 \\
\hline p16 & 1.34 & $(0.83,2.16)$ & 0.230 & 1.52 & $(0.83,2.80)$ & 0.178 \\
\hline JPH3 & 0.94 & $(0.57,1.56)$ & 0.817 & 1.40 & $(0.77,2.55)$ & 0.272 \\
\hline PCDH20 & 1.28 & $(0.87,1.89)$ & 0.217 & 1.40 & $(0.81,2.42)$ & 0.226 \\
\hline
\end{tabular}

Each row represents a separate adjusted model.

Analysis performed on combined cohorts.

*Additional adjustors include age, education, COPD, pack years, and cohort; $\mathrm{CMH}$ as outcome.

**Bonferroni adjusted significance threshold is $p<0.0042$.

a 3-gene model that included SULF2, JPH3, and $p 16$ as predictors, as well as age, pack years, education, and COPD (data not shown). Therefore, using the combined sample from the LSC and PLuSS, ROC curves were generated using the 3-gene model, the full 11-gene model, and covariates-only model in male former smokers (Figure 1). Likelihood ratio tests confirmed that both the 3-gene and 11-gene models are significantly more discriminative than the covariates only model $(\mathrm{p}=0.0002$ and $\mathrm{p}=0.002$, respectively); however, the 3 - and 11-gene models were not significantly different from each other $(p=0.29)$. Areas under the curve (AUC) were 0.74 and 0.80 for the 3 - and 11-gene models, respectively, while the AUC was 0.55 for the covariates only model. Although sample sizes were small in cohort-stratified analyses of male former smokers, these analyses demonstrate that the increased discriminative power of the 3-gene model is observed in two independent cohorts (Additional file 1: Figure S1).

\section{Discussion}

This study demonstrates a significant association between $\mathrm{CMH}$ and prevalence of promoter methylation in sputum of lung cancer risk genes in two geographically distinct cohorts. This association was especially strong in males and in former smokers, and SULF2 was the most consistently associated gene. Importantly, the overall association between $\mathrm{CMH}$ and methylation, and the specific effects of sex and smoking status, were observed independently in both cohorts. Combining the two cohorts strengthened the statistical significance of these associations. The central finding of our study is that male former smokers with unresolved $\mathrm{CMH}$ may be at an increased risk of lung cancer. Given that $50 \%$ of persons diagnosed with lung cancer are former smokers, prospective studies evaluating the methylation status of former smokers with $\mathrm{CMH}$ who subsequently develop lung cancer are needed [26].

The eleven genes examined in this study were selected based on prior evidence that they are associated with lung cancer risk $[17,18]$. Therefore, increased prevalence of methylation of these genes may predict lung cancer among subjects with $\mathrm{CMH}$. These gene promoters have all been shown to be methylated in tumors $[27,28]$, and

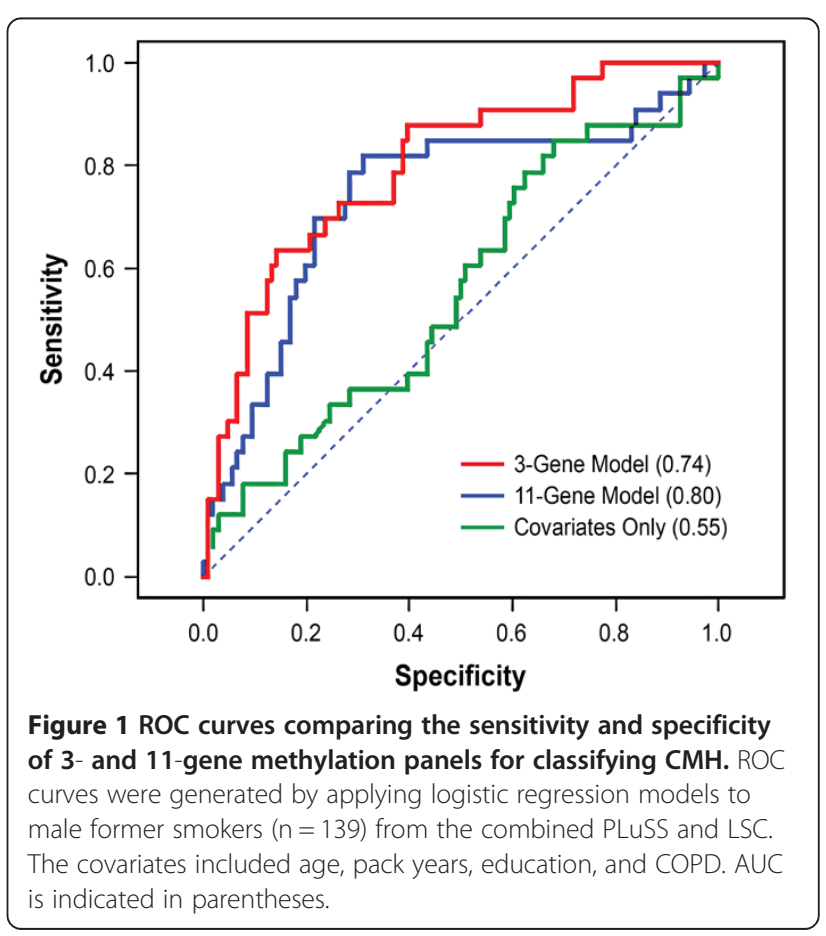


are proposed to represent an expanding field of precancerous epigenetic changes in the aerodigestive tract of smokers $[17,29]$. This hypothesis is supported by the observation that the methylation prevalence of these gene promoters increases as the time to lung cancer diagnosis decreases [17]. Mounting evidence indicates that these changes are causal for tumor initiation [30-33].

The association between methylation and $\mathrm{CMH}$ was markedly stronger in males than in females (Table 4). Univariate analysis of males and females in both cohorts (Additional file 1: Tables S3 and S4) reveals that females with $\mathrm{CMH}$ are significantly younger than female controls in the LSC; however this was not true in the PLuSS. Additionally age was a covariate in all adjusted analyses and thus is unlikely to account for the lack of association between methylation and $\mathrm{CMH}$ in females. This apparent protective mechanism in females warrants further study. The association between methylation and $\mathrm{CMH}$ was also stronger in former than in current smokers (Table 5). The increase in effect size in former smokers may be due to several reasons: (1) the $\mathrm{CMH}$ phenotype in former smokers may not be confounded by cough and phlegm caused by irritation due to current smoking; (2) in susceptible smokers, $\mathrm{CMH}$ that persists in spite of smoking cessation may represent a phenotype with a more distinct molecular pathology; (3) The association between $\mathrm{CMH}$ and gene promoter methylation may be stronger with age. In the LSC and PLuSS cohorts, former smokers were significantly older than current smokers (mean age difference 4.2 years, data not shown). This age difference between former and current smokers also likely explains the puzzling observation that current smokers have lower overall methylation compared to former smokers (Additional file 1: Table S2); current smokers are younger, and younger age is associated with less total methylation in these lung cancer risk genes.

Numerous studies have demonstrated that prior $\mathrm{CMH}$ significantly increases the risk for later development of lung cancer (reviewed in $[15,16]$ ). Assessment of the latency period between diagnosis of $\mathrm{CMH}$ and diagnosis of lung cancer has shown that this risk increases with time since diagnosis of $\mathrm{CMH}$ [34]. In one study [34], the odds ratio nearly quadrupled at latency $>15$ years compared to latency $1-5$ years. Importantly, this suggests that $\mathrm{CMH}$ may serve as a precursor to lung carcinogenesis [34]. We hypothesize that the increased prevalence for methylation of the lung cancer risk genes seen in this study may help explain the epidemiological link between $\mathrm{CMH}$ and lung cancer. Further studies are needed to establish a direct link between gene methylation and lung cancer. Interestingly, while SULF2, p16, JPH3, and PCDH20 all demonstrate evidence for association with $\mathrm{CMH}$ in the current study, a previous study determined that GATA4 promoter methylation was associated with airflow obstruction [35]. These findings suggest that major differences exist in the genes affected by aberrant promoter methylation in distinct COPD sub-phenotypes. This is consistent with the major pathophysiological differences that underlie emphysema and chronic mucous hypersecretion [36], and suggests the role basal cell hyperplasia may play in development of lung cancer [37].

Of the 11 genes analyzed, SULF2 demonstrated the strongest association with CMH. SULF-2 is an extracellular enzyme that catalyzes the hydrolysis of 6-O-sulfo groups from heparan sulfate polysaccharides [38-40]. Heparan sulfate proteoglycans (HSPGs) are widely distributed on cell membranes and the extracellular matrix, and serve as coreceptors for many growth factors and cytokines [41] and the position of 6-O sulfates is of particular importance for ligand binding [38-40]. Epigenetic inactivation of SULF2, either by siRNA treatment or promoter methylation, activates numerous type I interferon (IFN)-inducible genes [42]. It was proposed that silencing of SULF2 prevents the removal of sulfate groups from IFN-binding sites, which may preserve either the binding affinity or bioavailability of interferons leading to increased transcription of multiple IFN-inducible genes [42]. It is plausible that $\mathrm{CMH}$, caused by metaplastic mucous cells that are sustained due to dysregulated cell death mechanisms that involve IFN signaling [43-45], creates an inflammatory milieu which causes methylation of SULF2. In turn, the type 1 interferon response induced by methylation of SULF2 may help to perpetuate the inflammation associated with $\mathrm{CMH}$.

This is the first report of epigenetic changes in the airways of individuals with $\mathrm{CMH}$. Strengths of the study include the use of the large, well-characterized LSC for the initial phase of study and excellent replication of all main findings in the geographically distinct PLuSS. We chose the standard definition for chronic bronchitis in the LSC and a definition that most closely captured the standard clinical definition of chronic bronchitis in the PLuSS. While the differences in questionnaires used to define $\mathrm{CMH}$ could be considered a limitation in the study, the definition for $\mathrm{CMH}$ was applied to PLuSS subjects prior to any data analysis and was not subsequently modified. We propose that this approach improves the rigor of our validation. Replication of these findings supports the robustness of these markers for $\mathrm{CMH}$ and suggests that they are useful in defining a subset of subjects with $\mathrm{CMH}$ who could benefit from computed tomography $(\mathrm{CT})$ screening for lung cancer [46]. Indeed, low cost, gene-specific methylation screening assays could be incorporated into clinical practices for patients suspected to be at risk for lung cancer.

\section{Conclusions}

Especially male former smokers with persistent chronic mucous hypersecretion have markedly increased promoter methylation of lung cancer risk genes in cell obtained by 
sputum collection. These smokers may be at increased risk of lung cancer and may benefit from further tests for lung cancer, such as CT screening.

\section{Additional file}

Additional file 1: Table S1. Select variables by $\mathrm{CMH}$ status in the combined cohorts. Table S2. Select variables by high and low methylation tertile in combined cohorts. Table S3. Select variables by $\mathrm{CMH}$ in males from the LSC and PLUSS. Table S4. Select variables by $\mathrm{CMH}$ in females from the LSC and PLuSS. Figure S1. ROC curves comparing the sensitivity and specificity of the 3-gene methylation panels for classifying $\mathrm{CMH}$. ROC curves were generated by applying logistic regression models to male former smokers independently in the PLUSS ( $n=52)$ and LSC $(n=87)$. The covariates included age, pack years, education and COPD. AUC is indicated in parentheses.

\section{Competing interests}

The authors declare that they have no competing interests.

\section{Authors' contributions}

$Y T, S B$, and HP made substantial contributions to conception and design; SB, JW, JS, HP, SB, and MP made substantial contributions to acquisition of data or analysis and interpretation of data. All authors made substantial contributions to drafting the article or revising it critically for important intellectual content and final approval of the version to be published.

\section{Acknowledgements}

We would like to acknowledge the following individuals at Lovelace Scientific Resources, the Clinical Trials Division, for work in recruiting and collecting cohort data: Darlene Harbor (Site Director), Carmen Dubois and Linda Heath (Study Coordinators), Victor Lucero and Elia Casas (Lab Technicians), Tony Alonzo, Robin Adair, and Diane Griffith (Patient Recruitment), Leslie Bryant (Regulatory Coordinator), and Sarah Dechnik (Clinical Project Coordinator). This work was supported from funding by the State of New Mexico (appropriation from the Tobacco Settlement Fund), and from the National Institutes of Health (RO1 ES015482 to YT, R01 CA097356 to SB, HL107873-01 to YT and SB, and P50 CA090440 to JMS).

\section{Author details}

${ }^{1}$ Lovelace Respiratory Research Institute, Albuquerque, NM, Mexico. ${ }^{2}$ Department of Pharmacology \& Chemical Biology, Hillman Cancer Center of the University of Pittsburgh Medical Center, Pittsburgh, PA, USA.

Received: 12 September 2013 Accepted: 18 December 2013 Published: 9 January 2014

\section{References}

1. Murray CJ, Lopez AD: Global mortality, disability, and the contribution of risk factors: Global Burden of Disease Study. Lancet 1997, 349:1436-1442.

2. Mannino DM, Buist AS: Global burden of COPD: risk factors, prevalence, and future trends. Lancet 2007, 370:765-773.

3. Chan-Yeung M, Ait-Khaled N, White N, Ip MS, Tan WC: The burden and impact of COPD in Asia and Africa. Int J Tuberc Lung Dis 2004, 8:2-14.

4. Caballero A, Torres-Duque CA, Jaramillo C, Bolivar F, Sanabria F, Osorio P, Orduz C, Guevara DP, Maldonado D: Prevalence of COPD in five Colombian cities situated at low, medium, and high altitude (PREPOCOL study). Chest 2008, 133:343-349.

5. Dennis R, Maldonado D, Norman S, Baena E, Castano H, Martinez G, Velez J: Wood smoke exposure and risk for obstructive airways disease among women. Chest 1996, 109:55S-56S.

6. Bentayeb M, Simoni M, Baiz N, Norback D, Baldacci S, Maio S, Viegi G, Annesi-Maesano I: Geriatric Study in Europe on Health Effects of Air Quality in Nursing Homes G: Adverse respiratory effects of outdoor air pollution in the elderly. Int J Tuberc Lung Dis 2012, 16:1149-1161.

7. Agusti A, Calverley PM, Celli B, Coxson HO, Edwards LD, Lomas DA, MacNee W, Miller BE, Rennard S, Silverman EK, et al: Characterisation of COPD heterogeneity in the ECLIPSE cohort. Respir Res 2010, 11:122.
8. Curran DR, Cohn L: Advances in mucous cell metaplasia: a plug for mucus as a therapeutic focus in chronic airway disease. Am J Respir Cell Mol Biol 2010, 42:268-275.

9. Ekberg-Aronsson M, Pehrsson K, Nilsson JA, Nilsson PM, Lofdahl CG: Mortality in GOLD stages of COPD and its dependence on symptoms of chronic bronchitis. Respir Res 2005, 6:98.

10. Annesi I, Kauffmann F: Is respiratory mucus hypersecretion really an innocent disorder? A 22-year mortality survey of 1,061 working men. Am Rev Respir Dis 1986, 134:688-693.

11. Burgel PR, Nesme-Meyer P, Chanez P, Caillaud D, Carre P, Perez T, Roche N: Cough and sputum production are associated with frequent exacerbations and hospitalizations in COPD subjects. Chest 2009, 135:975-982.

12. Kim V, Han MK, Vance GB, Make BJ, Newell JD, Hokanson JE, Hersh CP, Stinson D, Silverman EK, Criner GJ: The Chronic Bronchitic Phenotype of COPD: An Analysis of the COPDGene Study. Chest 2011, 140:626-633.

13. Prescott $E$, Lange $P$, Vestbo J: Chronic mucus hypersecretion in COPD and death from pulmonary infection. Eur Respir J 1995, 8:1333-1338.

14. Guerra S, Sherrill DL, Venker C, Ceccato CM, Halonen M, Martinez FD: Chronic bronchitis before age 50 years predicts incident airflow limitation and mortality risk. Thorax 2009, 64:894-900.

15. Brenner DR, McLaughlin JR, Hung RJ: Previous lung diseases and lung cancer risk: a systematic review and meta-analysis. PLoS One 2011, 6:e17479.

16. Wang H, Yang L, Zou L, Huang D, Guo Y, Pan M, Tan Y, Zhong H, Ji W, Ran P, et al: Association between Chronic Obstructive Pulmonary Disease and Lung Cancer: A Case-control Study in Southern Chinese and a MetaAnalysis. PLoS One 2012, 7:e46144.

17. Belinsky SA, Liechty KC, Gentry FD, Wolf HJ, Rogers J, Vu K, Haney J, Kennedy TC, Hirsch FR, Miller Y, et al: Promoter hypermethylation of multiple genes in sputum precedes lung cancer incidence in a high-risk cohort. Cancer Res 2006, 66:3338-3344.

18. Leng S, Do K, Yingling CM, Picchi MA, Wolf HJ, Kennedy TC, Feser WJ, Baron $A E$, Franklin WA, Brock MV, et al: Defining a gene promoter methylation signature in sputum for lung cancer risk assessment. Clin Cancer Res 2012, 18:3387-3395.

19. Bruse S, Sood A, Petersen H, Liu Y, Leng S, Celedon JC, Gilliland F, Celli B, Belinsky SA, Tesfaigzi Y: New mexican Hispanic smokers have lower odds of chronic obstructive pulmonary disease and less decline in lung function than non-Hispanic whites. Am J Respir Crit Care Med 2011 184:1254-1260.

20. Hunninghake GM, Cho MH, Tesfaigzi Y, Soto-Quiros ME, Avila L, Lasky-Su J, Stidley C, Melen E, Soderhall C, Hallberg J, et al: MMP12, lung function, and COPD in high-risk populations. N Engl J Med 2009, 361:2599-2608.

21. Wilson DO, Weissfeld JL, Balkan A, Schragin JG, Fuhrman CR, Fisher SN, Wilson J, Leader JK, Siegfried JM, Shapiro SD, Sciurba FC: Association of radiographic emphysema and airflow obstruction with lung cancer. Am J Respir Crit Care Med 2008, 178:738-744.

22. Wilson DO, Weissfeld JL, Fuhrman CR, Fisher SN, Balogh P, Landreneau RJ, Luketich JD, Siegfried JM: The Pittsburgh Lung Screening Study (PLuSS): outcomes within 3 years of a first computed tomography scan. Am J Respir Crit Care Med 2008, 178:956-961.

23. Belinsky SA, Palmisano WA, Gilliland FD, Crooks LA, Divine KK, Winters SA, Grimes MJ, Harms HJ, Tellez CS, Smith TM, et al: Aberrant promoter methylation in bronchial epithelium and sputum from current and former smokers. Cancer Res 2002, 62:2370-2377.

24. Palmisano WA, Divine KK, Saccomanno G, Gilliland FD, Baylin SB, Herman JG, Belinsky SA: Predicting lung cancer by detecting aberrant promoter methylation in sputum. Cancer Res 2000, 60:5954-5958.

25. Burnham K, Anderson D: Multimodel Inference: Understanding AIC and BIC in Model Selection. Sociol Methods Res 2004, 33:261-304.

26. Alberg AJ, Brock MV, Ford JG, Samet JM, Spivack SD: Epidemiology of Lung Cancer: Diagnosis and Management of Lung Cancer, 3rd ed: American College of Chest Physicians Evidence-Based Clinical Practice Guidelines. Chest 2013, 143:e1S-e29S.

27. Tessema M, Yu YY, Stidley CA, Machida EO, Schuebel KE, Baylin SB, Belinsky SA: Concomitant promoter methylation of multiple genes in lung adenocarcinomas from current, former and never smokers. Carcinogenesis 2009, 30:1132-1138.

28. Belinsky SA, Grimes MJ, Casas E, Stidley CA, Franklin WA, Bocklage TJ, Johnson DH, Schiller JH: Predicting gene promoter methylation in non-small-cell lung cancer by evaluating sputum and serum. Br J Cancer 2007, 96:1278-1283. 
29. Slaughter DP, Southwick HW, Smejkal W: Field cancerization in oral stratified squamous epithelium; clinical implications of multicentric origin. Cancer 1953, 6:963-968.

30. Baylin SB, Herman JG, Graff JR, Vertino PM, Issa JP: Alterations in DNA methylation: a fundamental aspect of neoplasia. Adv Cancer Res 1998, 72:141-196.

31. Belinsky SA, Nikula KJ, Palmisano WA, Michels R, Saccomanno G, Gabrielson E, Baylin SB, Herman JG: Aberrant methylation of p16(INK4a) is an early event in lung cancer and a potential biomarker for early diagnosis. Proc Natl Acad Sci U S A 1998, 95:11891-11896.

32. Feinberg AP, Ohlsson R, Henikoff S: The epigenetic progenitor origin of human cancer. Nat Rev Genet 2006, 7:21-33.

33. Sharma S, Kelly TK, Jones PA: Epigenetics in cancer. Carcinogenesis 2010, $31: 27-36$.

34. Koshiol J, Rotunno M, Consonni D, Pesatori AC, De Matteis S, Goldstein AM, Chaturvedi AK, Wacholder S, Landi MT, Lubin JH, Caporaso NE: Chronic obstructive pulmonary disease and altered risk of lung cancer in a population-based case-control study. PLoS One 2009, 4:e7380.

35. Sood A, Petersen H, Blanchette C, Meek P, Picchi M, Belinsky SA, Tesfaigzi Y: Wood smoke exposure and gene promoter methylation are associated with increased risk for COPD in Smokers. Am J Resp Crit Care Med 2010. In Press.

36. Patel BD, Coxson HO, Pillai SG, Agusti AG, Calverley PM, Donner CF, Make BJ, Muller NL, Rennard SI, Vestbo J, et al: Airway wall thickening and emphysema show independent familial aggregation in chronic obstructive pulmonary disease. Am J Respir Crit Care Med 2008, 178:500-505.

37. Demoly P, Simony-Lafontaine J, Chanez P, Pujol J, Lequeux N, Michel F, Bousquet J: Cell proliferation in the bronchial mucosa of asthmatics and chronic bronchitics. Am J Respir Crit Care Med 1994, 150:214-217.

38. Morimoto-Tomita M, Uchimura K, Werb Z, Hemmerich S, Rosen SD: Cloning and characterization of two extracellular heparin-degrading endosulfatases in mice and humans. J Biol Chem 2002, 277:49175-49185.

39. Merry CL, Lyon M, Deakin JA, Hopwood JJ, Gallagher JT: Highly sensitive sequencing of the sulfated domains of heparan sulfate. J Biol Chem 1999, 274:18455-18462.

40. Sugaya N, Habuchi H, Nagai N, Ashikari-Hada S, Kimata K: 6-O-sulfation of heparan sulfate differentially regulates various fibroblast growth factordependent signalings in culture. J Biol Chem 2008, 283:10366-10376.

41. Bishop JR, Schuksz M, Esko JD: Heparan sulphate proteoglycans fine-tune mammalian physiology. Nature 2007, 446:1030-1037.

42. Tessema M, Yingling CM, Thomas CL, Klinge DM, Bernauer AM, Liu Y, Dacic S, Siegfried JM, Dahlberg SE, Schiller JH, Belinsky SA: SULF2 methylation is prognostic for lung cancer survival and increases sensitivity to topoisomerase-I inhibitors via induction of ISG15. Oncogene 2012, 31:4107-4116.

43. Harris JF, Fischer MJ, Hotchkiss JR, Monia BP, Randell SH, Harkema JR, Tesfaigzi Y: Bcl-2 sustains increased mucous and epithelial cell numbers in metaplastic airway epithelium. Am J Respir Crit Care Med 2005, 171:764-772.

44. Mebratu YA, Schwalm K, Smith KR, Schuyler M, Tesfaigzi Y: Cigarette smoke suppresses Bik to cause epithelial cell hyperplasia and mucous cell metaplasia. Am J Respir Crit Care Med 2011, 183:1531-1538.

45. Chand HS, Woldegiorgis Z, Schwalm K, McDonald J, Tesfaigzi Y: Acute Inflammation Induces Insulin-like Growth Factor- 1 to Mediate $\mathrm{Bcl}-2$ and Muc5ac Expression in Airway Epithelial Cells. Am J Respir Cell Mol Biol 2012, 47:784-791.

46. Aberle DR, Adams AM, Berg CD, Black WC, Clapp JD, Fagerstrom RM, Gareen IF, Gatsonis C, Marcus PM, Sicks JD: Reduced lung-cancer mortality with low-dose computed tomographic screening. N Engl J Med 2011, 365:395-409.

doi:10.1186/1465-9921-15-2

Cite this article as: Bruse et al:: Increased methylation of lung cancer-associated genes in sputum DNA of former smokers with chronic mucous hypersecretion. Respiratory Research 2014 15:2.

\section{Submit your next manuscript to BioMed Central and take full advantage of:}

- Convenient online submission

- Thorough peer review

- No space constraints or color figure charges

- Immediate publication on acceptance

- Inclusion in PubMed, CAS, Scopus and Google Scholar

- Research which is freely available for redistribution 